Kelaniya Journal of Human Resource Management

Volume 11, Number 02 - July 2016

DOI: http://doi.org/10.4038/kjhrm.v11i2.32

\title{
The Moderating Effects on the Relationship between Workplace Bulling and Intention to Leave
}

\author{
S. A. H. Kaushalya and Chamaru De Alwis ${ }^{1}$ \\ ${ }^{1}$ Department of Human Resource Management, University of Kelaniya, Sri Lanka \\ 1dealwisac@gmail.com
}

\begin{abstract}
Workplace Bulling (WB) is a major concern in any kind of organization because it leads to increase rate of turnover within the organization. However, there are certain factors, which affects to the employee retention in a workplace. This study was primarily focuses on identifying factors, which moderate employees' intention to leave from the organization. It was mainly using quantitative approach to conduct the research. Under first stage of the study, it has explored three factors, Organizational Commitment, Perceived Organizational support (POS) and Belief in a just World (BJW) as major factors to test in Sri Lankan Context. Population of the study was recently joined nurses (within three years form the data collection data) in the state hospitals in Sri Lanka. Using convenience-sampling method it was selected sample units. The analysis was done by using descriptive statistics and hierarchical multiple regression analysis. Results revealed that there is a statistically significant relationship between workplace bulling and intention to leave. Further, it confirm all three tested moderating factors statistically significant impact on the direct relationship from above mentioned three factors. In addition, it confirmed that that only BJW create significant impact on IL. Organizational commitment and POS become insignificant in combined effect. This Study can be concluded that there is a significant relationship between WB and $I L$ and it can be moderate by OC, POS and $B J W$.
\end{abstract}

Keywords: Workplace Bulling. Intention to Leave, Organizational Commitment, Organizational Support, Belief in a Just World 


\section{Background of the Study}

Workplace Bulling means "Process in which an employee is subjected to frequent negative acts for a relatively long period of time by peers and superiors against which defense or retaliation is hindered by the recognition of a power imbalance (Glambek et al., 2014). According to Edirisinghe and De Alwis (2015) quoted from GRC solutions (2014), workplace bulling is, "the repeated unreasonable behavior towards a worker that creates a risk to health and safety, but does not apply to reasonable management action carried out in a reasonable manner."

Edirisinghe and De Alwis (2015) confirms that WB creates negative impacts to both organization and employee. As per the Hatem and Orhan, (2012) in the perspective of the organization can create negative consequences like lower organizational citizenship behavior, reduce organizational satisfaction and commitment, decrease productivity, increase absenteeism and Intention to leave (IL) and finally increase turnover. Increased employee turnover creates a greater cost to the organization.

Many researchers provide evidence that there is a significant relationship between bullying and IL (Quine, 1999, 2001; Simons, 2008; Ocel and Aydin, 2012). IL means "deliberate willfulness to leave the organization (Mathias and Madden, 2015). Sujeewa (2011) stated that IL perceived as existing employees voluntary leave on their organizations. Employees, who are subject to a bullying behavior, have a higher intention to quit from the organization (Ocel and Aydin, 2012, Edirisinghe and De Alwis, 2015).

Further, Rasool et al (2013) stated that IL is the strong antecedent of turnover. Under that background, under this background, it was confirmed a strong relationship between WB and employee IL.

This study is focus on identifying factors that moderate this relationship between WB and IL. According to literature, there are three factors, which identified to moderate this relationship. Those are organizational commitment (OC), Perceived Organizational support (POS) and Belief in a just World (BJW).

According to Rasool et al., (2013) organizational commitment has a major impact on absenteeism and turnover and IL is an critical antecedent of actual 
turnover Further Rasool et al (2013) confirmed that highly committed employees have lower level of absenteeism and turnover.

BJW is another factor that moderates the relationship between WB and IL the organization. BJW means human need to view the world, as a just place in which individuals get what they deserve and de deserve what they get (Hatem and Orhan, 2012). BJW affect a lot to change employee personal characteristics. According to Lerner (1980), BJW making the world more practicable and sense of trust, hope and confidence within people. When people have trust, confidence and feeling of fair treatment by others, they tend to invest for their long term goals.

When employees have the BJW, they required others also treat them fairly. If they see or experience unfairness, they try to compensate it. If cannot compensate it, they reinterpret it fit with their belief of justice in the world (Hatem and Orhan, 2012).

POS is measured by extend to which organization value employee's contribution and cares about employees well-being etc. Studies prove that organization which has a supportive climate cause to less WB (Rhoades and Eisenberger, 2002). Role clarity, job information, participation in decisionmaking, support from co-workers and supervisors can be identified as dimensions of POS. These dimensions leads to increase job satisfaction, increase performance, increase commitment and reduce absenteeism and turnover. Therefor researchers focus on concept of POS as a key predictor of IL (Lena mari et al, 2011).

\section{Problem Statement}

As explained WB is a critical fact that causes to increase turnover within organization. That is why organizations put a serious attention on controlling bullying within organizations. When employees become a target of bullying, first they tend to be frustrated, create a feeling of isolation, lower productivity, less motivation to work, create an IL and finally leave the organization.

On the perspective of organization increase turnover cause to create additional cost of hiring, cost of giving training again and lower productivity until get trained etc. Therefore, managing WB is fundamental. Under this 
background, this study focused to identify what are the factors that moderate the relationship between WB and IL.

\section{Objectives of the Study}

This study is primarily based on recognizing factors that moderate the relationship between WB and IL. Based on this primary objective, there are specific objectives:

- To identify relationship between WB and IL among nurses in government hospitals Sri Lanka.

- To measure how OC, POS and BJW moderate the relationship between WB and IL among nurses in government hospitals Sri Lanka.

\section{Significance of the Study}

WB has become a significant contemporary issue for organizations now days. Therefor employers and management pay a serious attention towards effective dealing of bullying. When employees become a target of WB, they may be sensitive to the consequences of WB. It can create harmful psychological effects like low self-esteem, depression, suicidal thoughts (Mattiesen and Einarsen, 1999) and physical effects like stomach disorders, headache, musculoskeletal pains etc. These kind of negative consequences become a cause of low satisfaction, low productivity, increased absenteeism, low efficiency and effectiveness and finally creating a feeling of leaving from the organization. Therefor we can realize that those who become a target of bullying have higher IL (Quine, 1999) and create a threat to quit.

Therefore, management is trying to change employee's intention by attacking their personal feelings. When they are highly committed to the organization, they do not disappoint with anything. They only focus on their career development and organizational development. Furthermore, when they have a belief in a just environment, they tend to take up remedies for bullying at work by his own. When they see any unjust thing, immediately try to assimilate it. According to literature, people who have such feeling are more satisfied with their job and committed to the organization.

Therefore, the findings of this study helps in facilitating their working conditions by identifying their retention willingness in relevant organizations too. Organizations can introduce new policies, strategies that can be used to 
create a bullying free environment. Bullying free environments enhance employee's confidence. It is beneficial for both employee and employer for better performance.

\section{Conceptual Framework}

According to Edirisinghe and De Alwis (2015) cited evidence from Irshad (2012) mentioned that retaining an employee is very important than hiring as it consumes higher cost to orientate and train a new employee. There are various reasons, which affect or persuade employees to leave the organization and WB is one of the major factor that effect on employee IL. Therefore, as main concepts of this research researcher identified WB and IL.

In this study, WB was considered as the independent variable and defined it as any negative action characterized by power imbalance between the bully and the victim, occurs frequently over a period long period of time, feeling of isolation for the victim and result negatively for the organization and the victim both psychologically and physically.

As stated in literature, there is a direct relationship between WB and IL. When employees become a victim of a bullying behavior, they resign from the organization (Ongori, 2007). Therefore, under this conceptual framework IL recognize as dependent variable and defined it as IL is defined as the level to which a member contemplates leaving the relationship with current employer (Kim et al, 1996).

Even though WB cause to increase IL within an organization, there are factors, which moderate this relationship between WB and IL. OC, BJW and POS are some factors, which identified as moderators the exploratory study. Therefore, this study concerns, to what extend above mentioned factors moderate this relationship

Organizational commitment is a multi-faceted phenomenon, primarily associated with emotional bonding of the employee with the organization, eagerness to some additional work for the organization, the extent of objective and value congruency with the organization, and aspiration to associate with the organization (Rasool et al., 2013). Under this background, study recognized OC as the moderator of socalled relationship defined OC as employee's psychological 
attachment to the organization, because when employees are psychologically bound with the organization, they do not tend to leave the organization under any circumstances.

Employees do not leave the organization due to their belief about the just world. It means employees perceive the world as a just place to live that he can get what he deserves from employer. As well as BJW can be defined as individuals have a need to believe that they live in a world where people generally get what they deserve (Benabou \& Tirole, 2006). Employees with a strong BJW are more satisfied with their job and committed to the organization (Ocel \& Aydin, 2012).Therefore, IL shows a negative correlation with job satisfaction and organizational commitment. So it's reasonable to assume that IL can be moderate by employees' BJW (Ocel \& Aydin, 2012).

POS means, employee's sense of feeling that their organization is value and recognize their contribution, organization always try to create a supportive working condition within the organization.

POS can be defined as employees form opinions regarding the extent to which an organization values their contributions and cares about their well-being (Schalkwyk and Rothmann, 2011). When employees have the enough support from the organization, they tend to respond positively towards the organization, even though, they face any negative behavior within the organization frequently, they always try to behave for the betterment of the organization. POS can described by using role clarity, job information, participation in decision-making, colleague support and supervisory relationships (Schalkwyk, 2011). Employees who have these sub factors, have higher POS.

The following conceptual framework was developed to identify the relationships, if any, and the impact among the related variables of the research. The following operational definitions of the study variables were developed by the researcher and used in this study. 


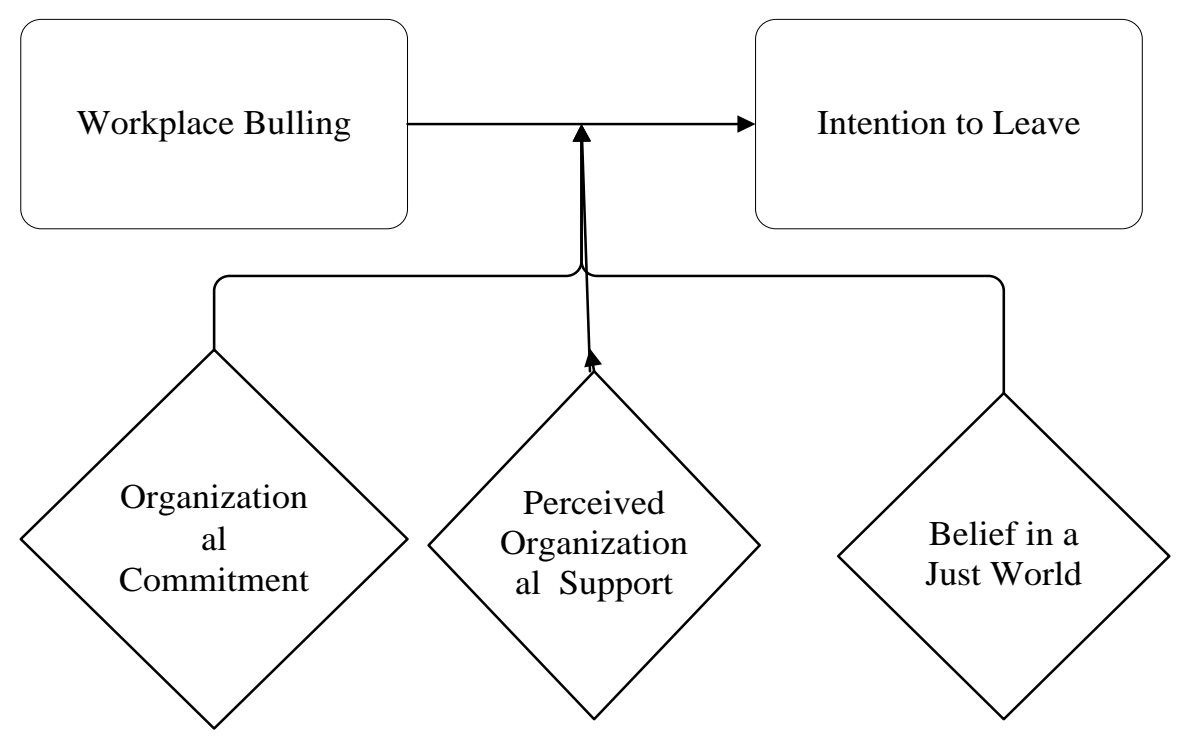

Figure 01: Conceptual Framework of the Study

Source: Developed by the researcher using expletory study

\section{Hypotheses Development}

Researcher developed hypotheses based on the conceptual framework stated above.

\section{Hypotheses 1: Relationship between Workplace Bulling (WB) and Intention to Leave (IL).}

Alternative hypothesis $\left(\mathrm{H}_{1 \mathrm{a}}\right)$ : There is a significant relationship between WB $(\mu \mathrm{WB})$ and $\mathrm{IL}(\mu \mathrm{TI})$

$$
\mathrm{H} 1: \mu \mathrm{WL} \neq \mu \mathrm{TI}
$$

\section{Hypotheses 2: Moderating Effects}

Alternative hypothesis $\left(\mathrm{H}_{2 \mathrm{a}}\right)$ : organizational commitment $(\mu \mathrm{OC})$ significantly moderates the relationship between WB $(\mu \mathrm{WB})$ and IL $(\mu \mathrm{TI})$.

$$
\mu \mathrm{TI}=\mu \mathrm{WB}+\mu \mathrm{OC}+(\mu \mathrm{WB} \mu \mathrm{OC})
$$

Alternative Hypothesis $\left(\mathbf{H}_{2 b}\right)$ : POS $(\mu \mathrm{POS})$ significantly moderates the relationship between WB $(\mu \mathrm{WB})$ and IL $(\mu \mathrm{TI})$.

$$
\mu \mathrm{TI}=\mu \mathrm{WB}+\mu \mathrm{POS}+(\mu \mathrm{WB} \mu \mathrm{POS})
$$


Alternative Hypothesis $\left(\mathbf{H}_{2 \mathbf{c}}\right)$ : $\mathrm{BJW}(\mu \mathrm{BJW})$ significantly moderates the relationship between $\mathrm{WB}(\mu \mathrm{WB})$ and $\mathrm{IL}(\mu \mathrm{TI})$.

$$
\mu \mathrm{TI}=\mu \mathrm{WB}+\mu \mathrm{BJW}+(\mu \mathrm{WB} \mu \mathrm{BJW}
$$

This study is mainly using quantitative approach to conduct the research. Researcher's interference for this study was very little. Because researcher only involved in preparing the questionnaire and distributed it in the natural working environment. Study was conducted in natural work environment where work proceeds normally. There would not be any interference to normal working conditions as survey method was used. This study was focused on nurses in the government hospitals in Sri Lanka as the target population. There are 31580 nurses currently working in government hospitals in Sri Lanka. Among them 21397 (68\%) nurses are working in line ministry and $10183(32 \%)$ are working in provincial hospitals. Convenience sampling method used by the researcher to select the sample from the target population. Sample was selected based on convenience sampling and distributed questionnaire among 127 nurses who recently joined and received just 110 . However, after proper screening only 100 questionnaires were used for the final analysis.

Data collection instrument was developed using previously constructed four questionnaires (Mowday et al, 1979; Dalbert, 1999; Liu, 2004). Section A of the questionnaire was designed to gather demographic data. Section B was designed to collect data under the variables WB, IL, organizational commitment, BJW and POS. It included 21 Likert-scale statements. After that, it was conducted a pilot study to check the reliability using twenty nurses because it was translated to Sinhala language. The results of the test were in between .734 and .906 .

\section{Data Analysis and Discussion}

\subsection{Descriptive Statistics}

In terms of age there are $65 \%(\mathrm{~N}=65)$ nurses who were age between $23-27$ and $35 \%(\mathrm{~N}=36)$ nurses who were over 28 years. Majority of respondents were between age 23-27.Age between 18-22 nurses not responded for the 
study. Further, $86 \%(\mathrm{~N}=86)$ of them were unmarried and $14 \%(\mathrm{~N}=14)$ married.

\subsection{Hypothesis Testing}

According to the above results of the Pearson Correlation Coefficient ( $\mathrm{r}$ value) 0.701 at a significant level of 0.01 which indicates that there is a strongly positive $(r>0.5)$ relationship exists between WB and IL. It proves that model is statistically significant. Hence, alternative hypothesis is accepted.

As per the test results of the Pearson Correlation Coefficient ( $r$ value)

Table 1: Model Summary

\begin{tabular}{|l|l|l|l|l|}
\hline \multicolumn{5}{|c|}{ Model Summary } \\
\hline Model & $\mathrm{R}$ & R Square & Adjusted R Square & $\begin{array}{l}\text { Std. Error of the } \\
\text { Estimate }\end{array}$ \\
\hline 1 & $.701^{\mathrm{a}}$ & .492 & .486 & .63896 \\
\hline \multicolumn{4}{|l}{ a. Predictors: (Constant), Workplace Bullying } \\
\hline
\end{tabular}

Source: Survey Data, 2015

As stated in the model summary, $\mathrm{R}^{2}$ value is 0.492 . As a percentage it is $49 \%$. It means that WB describes IL by $49.2 \%$ or WB explains $49.2 \% \%$ of the total variability of the Turnover Intension.

Table 2: The Model ANOVA between WB and IL

\begin{tabular}{|c|c|c|c|c|c|c|}
\hline \multicolumn{7}{|c|}{ ANOVA $^{\mathrm{a}}$} \\
\hline \multicolumn{2}{|c|}{ Model } & $\begin{array}{l}\text { Sum of } \\
\text { Squares }\end{array}$ & df & $\begin{array}{l}\text { Mean } \\
\text { Square }\end{array}$ & $\mathrm{F}$ & Sig. \\
\hline \multirow{3}{*}{1} & Regression & 38.677 & 1 & 38.677 & 94.734 & $.000^{\mathrm{b}}$ \\
\hline & Residual & 40.011 & 98 & .408 & & \\
\hline & Total & 78.688 & 99 & & & \\
\hline \multicolumn{7}{|c|}{ a. Dependent Variable: Intention to Leave } \\
\hline
\end{tabular}

Source: Survey Data, 2015 
The table 2 shows that Sig. value of the model is $\alpha=.000$ at $99 \%$ confidence level. Therefore, Sig. value is less than 0.00 at $99 \%$ confidence level $(0.000<$ 0.01 ) according to that the model is significant.

Table 3: Coefficient of WB and IL

\begin{tabular}{|c|c|c|c|c|c|c|}
\hline \multicolumn{7}{|c|}{ Coefficients } \\
\hline \multicolumn{2}{|c|}{ Model } & \multicolumn{2}{|c|}{$\begin{array}{l}\text { Unstandardized } \\
\text { Coefficients }\end{array}$} & \multirow{2}{*}{$\begin{array}{l}\text { Standardized } \\
\text { Coefficients } \\
\text { Beta } \\
\end{array}$} & \multirow[t]{2}{*}{$\mathrm{t}$} & \multirow[t]{2}{*}{ Sig. } \\
\hline & & B & Std. Error & & & \\
\hline \multirow{2}{*}{1} & (Constant) & .824 & .319 & & 2.585 & .011 \\
\hline & WB & .730 & .075 & .701 & 9.733 & .000 \\
\hline
\end{tabular}

Source: Survey Data, 2015

The above tables indicate to what extent, variation in WB influences the variance on IL. This explains that IL increases by 0.0 .73 points for each additional increase in the impact of WB. Further, this indicates that WB explains just $49.2 \%$ of the variance (R square) in IL. Hence, it can be clearly said that other factors have $50.8 \%$ influences on IL. Therefor it can be clearly said, that WB has, positive impact on IL. These results also justify that hypotheses one (H1) can be substantiated.

\subsection{Moderator Analysis}

\section{Moderate effect of Organizational Commitment to the relationship between $W B$ and $I L$}

Alternative hypothesis $\left(\mathrm{H}_{2 \mathrm{a}}\right)$ - Organizational commitment $(\mu \mathrm{OC})$ significantly moderates the relationship between workplace bullying $(\mu \mathrm{WB})$ and IL $(\mu \mathrm{TI})$.

$$
\mu \mathrm{TI}=\mu \mathrm{WB}+\mu \mathrm{OC}+(\mu \mathrm{WB} \mu \mathrm{OC})
$$


Table 4: Model ANOVA between organizational Commitment and IL

\begin{tabular}{|l|l|r|r|r|r|r|}
\hline \multicolumn{2}{|l|}{ Model } & \multicolumn{1}{|c|}{$\begin{array}{l}\text { Sum of } \\
\text { Squares }\end{array}$} & \multicolumn{1}{c|}{ df } & $\begin{array}{c}\text { Mean } \\
\text { Square }\end{array}$ & F & Sig. \\
\hline \multirow{3}{*}{1} & Regression & 32.198 & 1 & 32.198 & 67.873 & $.000^{\mathrm{b}}$ \\
\cline { 2 - 7 } & Residual & 46.490 & 98 & .474 & & \\
\cline { 2 - 7 } & Total & 78.688 & 99 & & & \\
\hline \multicolumn{7}{|l}{ a. Dependent Variable: IL } \\
\hline
\end{tabular}

Source: Survey Data, 2015

The Hierarchical Multiple Regression Model was used to find whether organizational commitment significantly moderate the relationship between WB and IL. The table 4 shows that Sig. value of the model is $\alpha=.000$ at $99 \%$ confidence level. Therefore, Sig. value is less than 0.00 at $99 \%$ confidence level $(0.000<0.01)$. Results indicated that interaction between WB to organizational commitment $(b=.112, \mathrm{SEb}=.014, \beta=.640, \mathrm{p}<.01)$ were associated with IL. These results indicated that relationship between WB and IL was moderated by organizational commitment. Therefore, alternative hypothesis (H2a) was accepted.

Table 5: Model summary organizational commitment and IL

\begin{tabular}{|l|r|r|r|c|}
\hline \multicolumn{5}{|c|}{ Model Summary } \\
\hline \multicolumn{1}{|c|}{ Model } & \multicolumn{1}{|c|}{$\mathrm{R}$} & \multicolumn{1}{c|}{ R Square } & Adjusted R Square & $\begin{array}{c}\text { Std. Error of the } \\
\text { Estimate }\end{array}$ \\
\hline 1 & $.640^{\mathrm{a}}$ & .409 & .403 & .68876 \\
\hline \multicolumn{2}{|l|}{ a. Predictors: (Constant), Organizational Commitment } \\
\hline
\end{tabular}

Source: Survey Data, 2015

As per the results, $\mathrm{R}^{2}$ value is $0.409(40.9 \%)$. It means organizational commitment explains IL by $40.9 \%$. It describes model summary of WB and $\mathrm{IL}, \mathrm{R}^{2}$ value is $0.492(49.2 \%)$. These results shows, organizational commitment reduces the impact built on direct relationship between WB and IL by 0.083 (0.492-0.409). As a percentage $8.3 \%$. Therefore, organizational commitment reduced the impact of WB on IL. 


\section{Moderate effect of Perceived organizational support (POS) to the relationship between Workplace Bullying and Intention to leave}

Alternative hypothesis $\left(\mathrm{H}_{2 \mathrm{~b}}\right)$ : Perceived organizational support ( $\mu \mathrm{POS}$ ) significantly moderates the relationship between workplace bullying $(\mu \mathrm{WB})$ and Intention to leave $(\mu \mathrm{TI})$.

$$
\mu \mathrm{TI}=\mu \mathrm{WB}+\mu \mathrm{POS}+(\mu \mathrm{WB} \mu \mathrm{POS})
$$

Table 6: Coefficient of perceived organizational support and Intention to leave

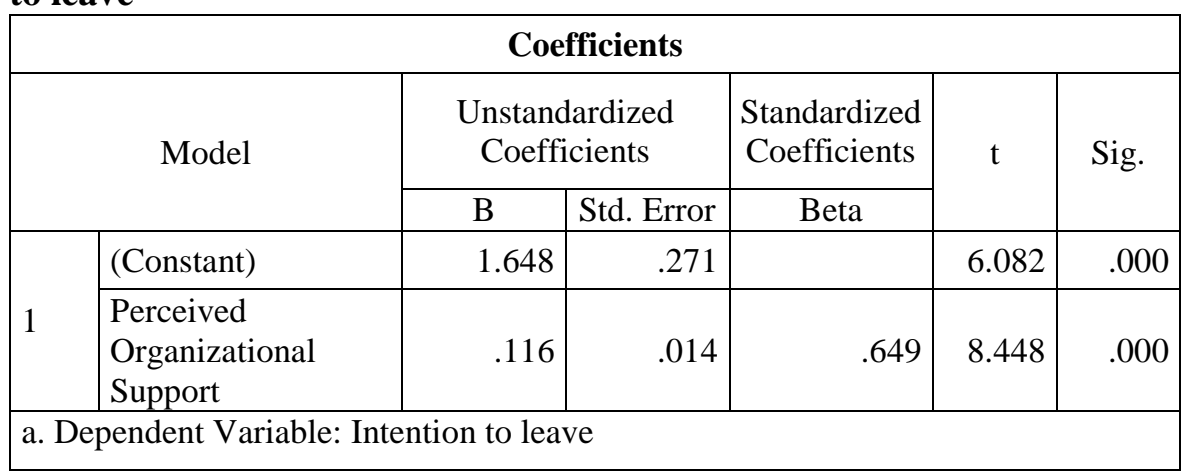

Source: Survey Data, 2015

In order to identify moderator effect of perceived organizational support on relationship between workplace bullying and Intention to leave used moderated multiple regression model. Based on the findings identified that perceived organizational support $(b=.116, \mathrm{SEb}=.014, \beta=.649, \mathrm{p}<.01)$ was associated with Intention to leave. Therefore, interaction between perceived organizational support and workplace bullying was significant $(0.000<0.01)$. These results indicated that relationship between workplace bullying and Intention to leave was moderated by organizational commitment. Therefore, alternative hypothesis (H2b) was accepted. 
Table 7: Model summary perceived organizational support and Intention to leave

\begin{tabular}{|l|r|r|r|r|}
\hline \multicolumn{7}{|c|}{ Model Summary } \\
\hline \multicolumn{1}{|c|}{ Model } & \multicolumn{1}{|c|}{ R } & R Square & Adjusted R Square & $\begin{array}{c}\text { Std. Error of the } \\
\text { Estimate }\end{array}$ \\
\hline 1 & $.649^{\mathrm{a}}$ & .421 & .415 & .68163 \\
\hline \multicolumn{2}{|l}{ a. Predictors: (Constant), Perceived Organizational Support } \\
\hline
\end{tabular}

Source: Survey Data, 2015

$\mathrm{R}^{2}$ value for perceived organizational support was .421 (42.1\%).It reveals that perceived organizational support (Moderator variable 2) explains $42.1 \%$ of the total variability of the Turnover Intension (dependent variable). According to the table 7, $\mathrm{R}^{2}$ value is 0.492 (49.2\%). These results shows, perceived organizational support reduces the impact build on direct relationship between workplace bullying and Intention to leave by 0.071 (0.492-0.421).As a percentage $7.1 \%$.Therefore, perceived organizational support reduced the impact of workplace bullying on Intention to leave.

\section{Moderate effect of Belief in a Just World to the relationship between Workplace Bullying and Intention to leave}

Alternative hypothesis $\left(\mathrm{H}_{2 c}\right)$ : Belief in a just world ( $\left.\mu \mathrm{BJW}\right)$ significantly moderates the relationship between workplace bullying ( $\mu \mathrm{WB})$ and Intention to leave $(\mu \mathrm{TI})$.

$$
\mu \mathrm{TI}=\mu \mathrm{WB}+\mu \mathrm{BJW}+(\mu \mathrm{WB} \mu \mathrm{BJW}
$$

Table 8: ANOVA between Belief in a Just World and Intention to leave

\begin{tabular}{|c|c|c|c|c|c|c|}
\hline \multicolumn{7}{|c|}{ ANOVA $^{\mathrm{a}}$} \\
\hline & Model & $\begin{array}{l}\text { Sum of } \\
\text { Squares }\end{array}$ & df & $\begin{array}{l}\text { Mean } \\
\text { Square }\end{array}$ & $\mathrm{F}$ & Sig. \\
\hline \multirow{3}{*}{1} & Regression & 39.810 & 1 & 39.810 & 100.350 & $.000^{\mathrm{b}}$ \\
\hline & Residual & 38.878 & 98 & .397 & & \\
\hline & \begin{tabular}{|l|} 
Total \\
\end{tabular} & 78.688 & 99 & & & \\
\hline \multicolumn{7}{|c|}{ a. Dependent Variable: Intention to leave } \\
\hline & & & & & & \\
\hline
\end{tabular}

Source: Survey Data, 2015 
The Hierarchical Multiple Regression Model was used to find whether perceived organizational support significantly moderate the relationship between workplace bullying and Intention to leave. Results shows that Sig. value of the model is $\alpha=.000$ at $99 \%$ confidence level. Therefore, Sig. value was less than 0.00 at $99 \%$ confidence level $(0.000<0.01)$.According to that the model is significant.

Table 9: Coefficient of belief in a Just world and Intention to leave

\begin{tabular}{|c|c|c|c|c|c|c|}
\hline \multicolumn{7}{|c|}{ Coefficients } \\
\hline \multirow{2}{*}{\multicolumn{2}{|c|}{ Model }} & \multicolumn{2}{|c|}{$\begin{array}{l}\text { Unstandardized } \\
\text { Coefficients }\end{array}$} & \multirow{2}{*}{$\begin{array}{l}\text { Standardized } \\
\text { Coefficients } \\
\text { Beta }\end{array}$} & & \multirow[t]{2}{*}{ Sig. } \\
\hline & & $\mathrm{B}$ & Std. Error & & & \\
\hline \multirow[b]{2}{*}{1} & (Constant) & 1.743 & .221 & & 7.892 & .000 \\
\hline & $\begin{array}{l}\text { Belief in a Just } \\
\text { World }\end{array}$ & .118 & .012 & .711 & 10.017 & .000 \\
\hline
\end{tabular}

Source: Survey Data, 2015

Results indicated that interaction between workplace bullying to belief in a just world $(b=.118, \mathrm{SEb}=.012, \beta=.711, \mathrm{p}<.01)$ were associated with intention to leave. These results indicated that relationship between workplace bullying and Intention to leave was moderated by belief in a just world. Therefore, alternative hypothesis $(\mathrm{H} 2 \mathrm{c})$ was accepted.

$\mathrm{R}^{2}$ value for belief in a just world was $0.506(50.6 \%)$.It means belief in a just world (moderator variable 3 ) explains Intention to leave by $50.6 \%$. As stated in the model summary of workplace bullying and Intention to leave, $\mathrm{R}^{2}$ value is $0.492(49.2 \%)$. These results shows, belief in a just world increases the impact built on direct relationship between workplace bullying and Intention to leave by $0.014(0.506-0.492)$.As a percentage $1.4 \%$.It means that even though moderator is significant $(\mathrm{p}<0.01)$, impact created by bullying on intention to quit had increased. Therefore, belief in a just world increased the impact of workplace bullying on Intention to leave. 
Moderate effect combination of Perceived Organizational Support, Belief in a Just World to the relationship between Workplace Bullying and Intention to leave

Table 10: Coefficient of combination effect of moderator variables on Intention to leave

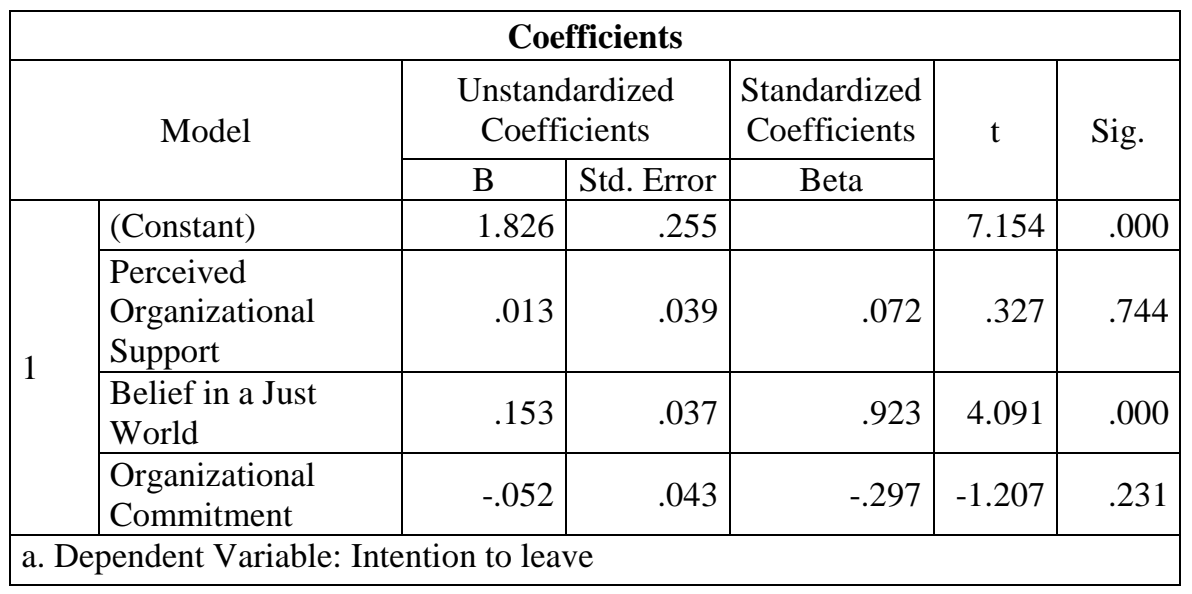

Source: Survey Data, 2015

The Hierarchical Multiple Regression Model was used to find whether combined effect of all three moderating factors (perceived organizational support, belief in a just world and organizational commitment) significantly moderate the relationship between workplace bullying and Intention to leave. According to the results, both organizational commitment $(0.231>0.01)$ and perceived organizational support (0.744>0.01) was not significant. But, belief in a just world shows that sig value of the model is $\alpha=.000$ at $99 \%$ confidence level. Therefore, Sig. value was less than 0.00 at $99 \%$ confidence level $(0.000<0.01)$.According to that the belief in a just world remains significant. Standardize coefficient of beta value also highest $(\beta=.923)$.

Therefore, All the moderating factors (perceived organizational support, belief in a just world and organizational commitment) were significantly moderate the direct relationship when consider individually. But, combined effect of all three, perceived organizational support and organizational commitment were not significant $(\mathrm{p}>.01)$ and belief in a just world remains significant $(\mathrm{p}<.01)$. 


\section{Conclusion}

WB is a serious issue, which causes organizations to even shut down their operations. Therefore, successful management is a critical need to minimize adverse consequences of WB. This study primarily focuses on identifying factors that moderate the direct relationship between WB and IL.

Objectives of the study were achieved and findings revealed that there is a strong positive relationship between WB and IL. It reflects that nurses who become target of bullying have higher intention to quit. Intention to quit is a strong antecedent of turnover. Other studies regarding WB and IL also justify that there is a positive impact of WB on IL (Rasool et al., 2013). Therefore, emerging a feeling of leaving, create a high threat for organization. Because human resources or manpower is the strongest resource for gaining competitive advantage. However, this relationship can be moderate by organizational commitment, POS and BJW. So Second, third and fourth hypotheses are developed in order to achieve mentioned objectives.

Findings reveal that organizational commitment is a statistically significant model which stated direct relationship between WB and IL can be weaken with the interference of organizational commitment. Furthermore, this result substantiates the validity and generalizability of this study as we have yielded similar results to other research. Previous studies provides an insight that the harmful effects of WB could be handled effectively through the moderating effects of organizational commitment on the relation between WB and IL (Rasool et al., 2013). This study also provides evidence of the existence of a moderating effect of POS on the relationship between WB and IL. POS is statistically significant and leads to weak the direct relationship between WB and IL by $7.1 \%$.Previous studies regarding this has justify that POS significantly moderate employees' intention to quit (Schalkwyk et al., 2012). Furthermore, research findings reveal that BJW statistically significant but strengthen the relationship between WB and IL. Even though the moderating factors are statistically significant when consider individually, combined effect of all three factors reveal that only BJW statistically significant and other two variables become insignificant. 
Finally, it can be concluded that there is a significant relationship between WB and IL and it can be moderate by organizational commitment, POS and BJW in case of nurses in government hospitals.

\section{References}

Be'nabou, Roland, and Jean Tirole. 2002. "Self- 1676 THE AMERICAN ECONOMIC REVIEW DECEMBER 2006 Confidence and Personal Motivation." Quarterly Journal of Economics, 117(3): 871-915

Berthelsen, M., Skogstad, A., Lau, B., \& Einarsen, S. (2011). Do they stay or do they go? A longitudinal study of intentions to leave and exclusion from working life among targets of WB. International Journal of Manpower, 178193.

Edirisinghe P, De Alwis A.C (2015) Factors influence on employee retention in a bullied workplace: an empirical investigation in private sector organizations in Sri Lanka, Journal of Cooperate Management and Economics,2, vii

Glambek, M., Matthiesen, S. B., Hetland, J., \& Einarsen, S. (2014). WB as an antecedent to job insecurity and IL: a 6-month prospective study. Human Resource Management Journal, 255-268.

Kim, Sang-Wook, James L. Price, Charles W. Mueller and Thomas W. Watson. 1996. "The Determinants of Career Intent among Physicians at a U.S. Air Force Hospital.” Human Relations 49(7):947-976.

Lena-Mari V S, Crizelle E, Ian R(Jr) ( 2011), The moderating role of perceived organizational support in the relationship between workplace bullying and turnover intention across sectors in South Africa, SA Journal of Human Resource Management; Vol 9, No 1 (2011), 13 pages. doi: 10.4102/sajhrm.v9i1.384

Liu, W. (2004). POS: Linking Human Resource Management Practices With Important Work Outcomes.

Madden, L., Mathias, B. D., \& Madden, T. M. (2015). In good company: The impact of perceived organizational support and positive relationships at work on turnover intentions. Management Research Review, 38(3), 242-263. http://dx.doi.org/10.1108/MRR-09-2013-02.

Mowday, Steers, \& Porter. (1979). The Organizational Commitment Questionnaire.

Ocel, H., \& Aydin, O. (2012). Workplace bullying and turnover intention: The moderating role of belief in a just world. International Journal of Business and Social Science, 3(13), 248-258. 
Kelaniya Journal of Human Resource Management

Volume 11, Number 02 - July 2016

Ongori H. (2007). A review of the literature on employee turnover, Afri. J. Bus. Manage. 1(3): 49-54.

Perryer, C., Jordan, C., Firns, I., \& Travaglione, A. (2010). Predicting TIs - The interactive effects of organizational commitment and POS. Management Research Review, 911-923.

Quine L (1999) Workplace bullying in NHS community trust: Staff questionnaire survey Article in BMJ Clinical Research · January 1999 DOI: 10.1136/bmj.318.7178.228.

Rasool, F; Arzu, F; Hasan, A; Rafi, A; Kashif, Abdul R. (2013) Information Management and Business Review; Dubai 5.4 : 175-180.

Rhoades, L., \& Eisenberger, R. 2002. Perceived organizational support: A review of the literature. Journal of Applied Psychology, 87: 698-714.

Schalkwyk L.M.V., Els C. \& Rothmann I. (2011). The moderating role of perceived organizational support in the relationship between workplace bullying and turnover intention across sectors in South Africa. Journal of Human Resource Management/SA, 384-397.

Schalkwyk, L.-M. v. (2011). The moderating role of perceived organisational support in the relationship between WB and IL across sectors in South Africa.

Schalkwyk, L.-M. v., Els, C., \& Rothmann, I. (2011). The moderating role of perceived organisational support in the relationship between WB and IL across sectors in South Africa. SA Journal of Human Resource Management.

Simons, S. (2008). Workplace bullying experienced by Massachusetts registered nurses and the relationship to intention to leave the organization. Advances in Nursing Science, 31(2), E48-E59. doi:

10.1097/01.ANS.0000319571.37373.d7

Sujeewa, W. (2011). Relationship between Human Resource Management Practices, Non - Managerial Employee Intention to Turnover in Garment Industry in Sri Lanka, pp 535-539. 